\title{
Die polymorbide Persönlichkeit
}

Lilly Zimmerli

Ärztin, 90 Jahre

"Sie leben hoch», dachte ich heute morgen, als ich nach gutem Schlaf meine steifen Glieder wieder in Aktion brachte. Beim Aufstehen begrüsste ich die zwei ungleich dicken Beine, das sehr schlanke, um nicht zu sagen «dürre», mit dem arthrotisch krummen Knie, das neidisch nach innen schielte zum Kunstgelenk am rechten Bein, das ich so mühelos aus dem Bett streckte. Dann verglich ich das dicke, das mit dem Kunstknie, mit dem dünnen. Ohne Stützstrumpf sah es unschön aus. Ich wusste aber, dass es nach dem mühsamen Anziehen des Strumpfkorsetts recht nett aussehen wird.

Die Füsse sehnten sich nach den Schuhen mit den Spezialeinlagen.

Schon hörte ich die Vögel pfeifen, nachdem ich den noch ruhenden Hörapparat wieder in Funktion brachte im linken Ohr.

Die neue Brille nach beidseitiger Staroperation liess mich alles klar erkennen.

Die beiden knarrenden Hüftgelenke taten ihren Dienst heute morgen recht gut.

In meinen weissen Haaren wehrten sich immer noch ein paar dunkle, wohl um mich zu erinnern, wie es früher aussah.

Das Herz pumpt zwar am Morgen immer ein wenig mühsam, doch langt es gut, um die recht vielen Treppen im Haus zu meistern.
Also als Ganzes gesehen, bin ich noch eine recht zufriedene Person. Ich kann mich gut bewegen, kann darüber nachdenken, dass es gut ist, mehrere Leiden zu haben, denn so heben sie sich gegenseitig fast ein wenig auf, und man nimmt sie nicht so wichtig. Wäre nur ein Schaden vorhanden, würde man ihn wohl zu sehr beachten.

Mit grosser Dankbarkeit setze ich mich an den Tisch, den mein lieber, am Stock gehender, nicht mehr so strammer Ehemann liebevoll zum Morgenessen bereit gemacht hat. Wir sitzen dann gemütlich zusammen, machen Pläne für den Tag, sind dankbar für die gut erlebte Nacht.

Ja, und zwei Tage später geschah es! Eine freche «Gürtelrose» setzte sich auf meine linke Hüfte und brachte mit ihrem heftigen Schmerz das offenbar doch ziemlich labile Gleichgewicht durcheinander. Doch hatte ich wieder grosses Glück, denn zwei nette Ärzte, mein Mann und mein Sohn, erkannten sofort, um was es sich handelte, und ich schluckte, zwar widerwillig, grosse, weisse Tabletten, eine Woche lang!

Und jetzt, vier Wochen später, ist der Spuk vorbei. Rote Bläschen und Schmerz sind verschwunden. Die Energie lässt noch etwas zu wünschen übrig, aber Zuversicht und Gleichgewicht sind wieder hergestellt, und es gilt wieder: Beim Morgenessen sitzen wir zusammen, sind dankbar für die gute Nacht und machen Pläne für den neuen Tag.

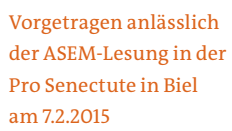

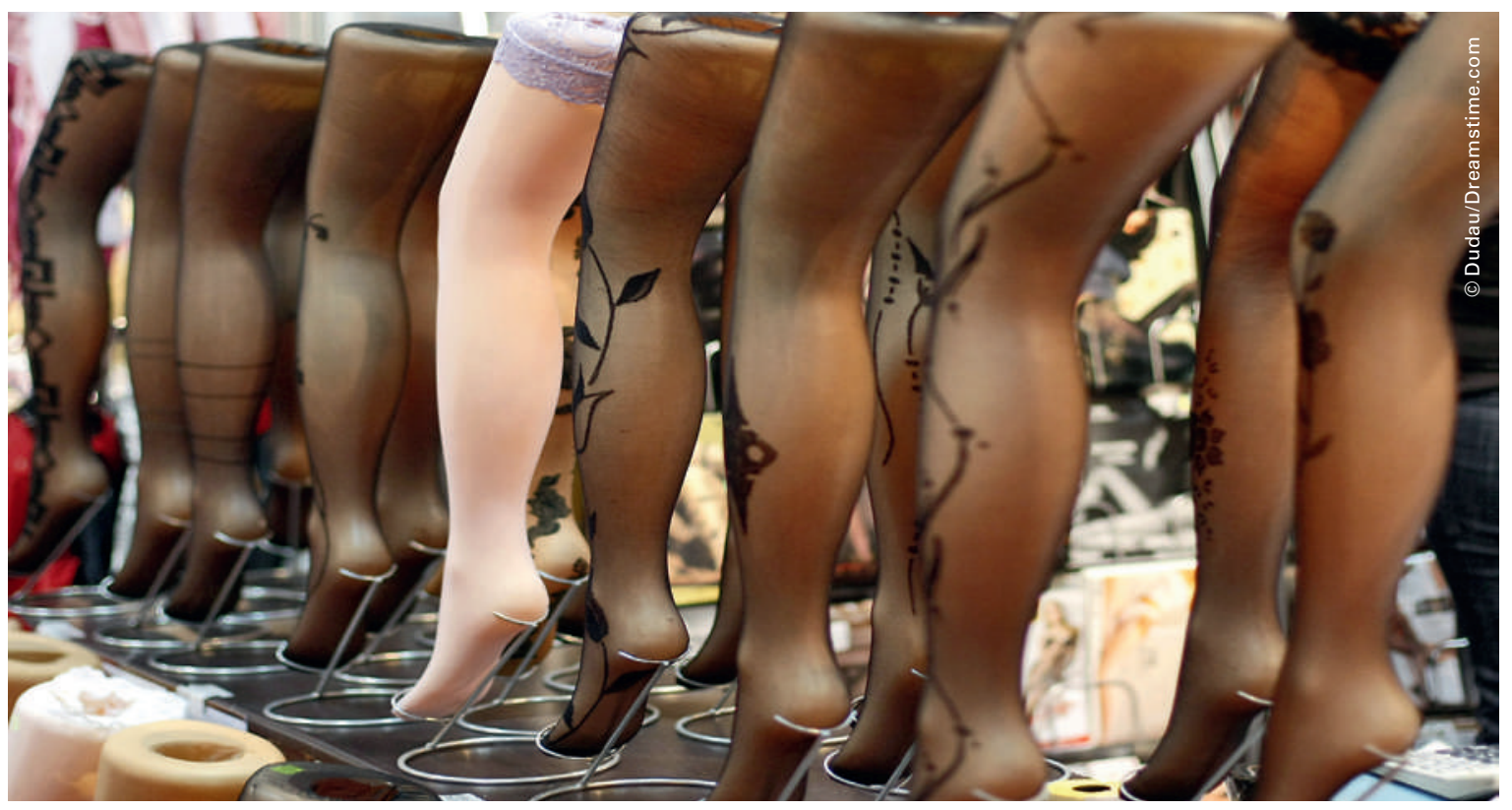

Tempi passati - heute lieber Stützstrümpfe .. 